\title{
Antibacterial properties of silver nanoparticles synthesized using Pulicaria glutinosa plant extract as a green bioreductant
}

This article was published in the following Dove Press journal:

International Journal of Nanomedicine

28 July 2014

Number of times this article has been viewed

\author{
Mujeeb Khan' \\ Shams Tabrez Khan ${ }^{2}$ \\ Merajuddin Khan' \\ Syed Farooq Adil' \\ Javed Musarrat ${ }^{2}$
}

Abdulaziz A Al-Khedhairy ${ }^{2}$

Abdulrahman Al-Warthan'

Mohammed Rafiq $\mathrm{H}$

Siddiqui'

Hamad Z Alkhathlan'

'Department of Chemistry, ${ }^{2}$ Zoology Department, College of Science, King Saud University, Riyadh, Kingdom of Saudi Arabia
Correspondence: Hamad Z Alkhathlan Department of Chemistry, College of Science, King Saud University, PO 2455, Riyadh I I45I, Kingdom of Saudi Arabia

Tel +966 | 4675910

Fax +966 | 4675992

Email khathlan@ksu.edu.sa

\begin{abstract}
The antibacterial properties of nanoparticles (NPs) can be significantly enhanced by increasing the wettability or solubility of NPs in aqueous medium. In this study, we investigated the effects of the stabilizing agent on the solubility of silver NPs and its subsequent effect on their antimicrobial activities. Silver NPs were prepared using an aqueous solution of Pulicaria glutinosa plant extract as bioreductant. The solution also acts as a capping ligand. During this study, the antimicrobial activities of silver NPs, as well as the plant extract alone, were tested against Escherichia coli, Pseudomonas aeruginosa, Staphylococcus aureus, and Micrococcus luteus. Silver NPs were prepared with various concentrations of the plant extract to study its effect on antimicrobial activity. Interestingly, various concentrations of $P$. glutinosa extract did not show any effect on the growth of tested bacteria; however, a significant effect on the antimicrobial property of plant extract capped silver NPs (Ag-NPs-PE) was observed. For instance, the half maximal inhibitory concentration values were found to decrease (from $4 \%$ to $21 \%$ ) with the increasing concentrations of plant extract used for the synthesis of Ag-NPs-PE. These results clearly indicate that the addition of $P$. glutinosa extracts enhances the solubility of Ag-NPs-PE and, hence, increases their toxicity against the tested microorganisms.
\end{abstract}

Keywords: antibacterial activity, silver nanoparticles, plant extract, Pulicaria glutinosa

\section{Introduction}

Among the greatest health challenges in recent times, and one of the most serious concerns, is the emergence of antibiotic-resistant bacteria that have developed resistance against many conventional antibacterial agents. ${ }^{1-4}$ This has prompted the advancement of alternative strategies, including the application of nanoparticles (NPs) as antimicrobial agents. ${ }^{5}$ Because of their high surface-to-volume ratio and unique physical and chemical properties, which are different from their bulk properties, NPs have demonstrated excellent antimicrobial activity. ${ }^{6-9}$ Several types of nanomaterials and their composites, including copper, zinc, titanium, gold, and silver, have been applied as antimicrobial agents. ${ }^{10-13}$ Despite some genuine concern regarding their toxicity, ${ }^{14}$ silver NPs exhibit excellent antimicrobial activity against bacteria, viruses, and other eukaryotic microorganisms. ${ }^{15-18}$

Numerous studies have attempted to explain the mechanisms by which silver NPs exert their antibacterial activities. ${ }^{19-21}$ In general, the surface area of the NPs and their ability to effectively release silver ions is the key to their antibacterial activity. The extremely large surface area of NPs facilitates better contact with microorganisms, because of which NPs get easily attached to the cell membrane and also penetrate inside the bacteria. ${ }^{22}$ The release of ionic silver inactivates vital bacterial enzymes, inhibits 
DNA replication, and also damages the bacterial cytoplasmic membranes, which ultimately causes cell death. ${ }^{19}$

Previous studies have suggested that the size, ${ }^{23}$ morphology, ${ }^{24}$ surface charge, ${ }^{25}$ and surface coating ${ }^{26}$ of the silver NPs play critical roles in determining their antibacterial activities. Furthermore, the bactericidal properties of the silver NPs also depend on their stability and solubility in the growth medium, which renders greater retention time for the interaction between bacteria and NPs. ${ }^{27,28}$ In general, the stabilization of NPs is achieved via surface functionalization of the NPs, using various capping agents that bind to the surface of the NPs and inhibit their aggregation by enhancing their stability and water solubility. ${ }^{29}$ Moreover, it has also been suggested that the antibacterial activity of the silver NPs can be significantly enhanced by the proper choice and control of stabilizing agents. ${ }^{30}$ However, the effect of stabilizing agents on the antimicrobial activities of the silver NPs, such as the nature of the stabilizing ligands, their concentration, and many other factors, has been rarely studied. ${ }^{30}$

Several methods were applied for the preparation of silver NPs, and most of them involve the chemical reduction of silver salts. ${ }^{31,32}$ Usually, in such methods, stabilization of NPs is carried out via additional capping agents, such as water-soluble polymers, oligosaccharides, polysaccharides, sodium dodecyl sulfate, cyclodextrin, and so on. ${ }^{30,33}$ However, such chemical methods imply toxic chemicals, hazardous conditions, and costly apparatus in comparison to the green synthesis of silver NPs involving biocompatible ingredients under the physiological conditions of temperature and pressure. Moreover, the biologically active molecules involved in the synthesis of NPs, especially phytomolecules, that are present in the plant extract (PE) often act as functionalizing ligands, thereby limiting the use of any external capping agents. ${ }^{34}$ Therefore, the demand for the green synthesis of silver NPs has been ever increasing. ${ }^{35,36}$

In our previous studies, we demonstrated a facile and ecofriendly synthesis of silver NPs using an aqueous solution of Pulicaria glutinosa PE as a bioreductant (Figure 1). ${ }^{37}$ Detailed investigations of the effect of concentration of the reductant (PE) on the morphology and kinetics of reaction revealed that the concentration of the PE exerts a significant effect on the size and dispersion of NPs, and at higher concentration of PE, fewer aggregated NPs were formed. Furthermore, it has been confirmed, via different characterization techniques, that the $\mathrm{PE}$ not only acts as a bioreductant but also functionalizes the NPs surfaces, acting as a capping ligand to stabilize them in the solvent.



Pulicaria glutinosa plant

Plant extract residue



$\mathrm{T}=90^{\circ} \mathrm{C}, \mathrm{t}=2$ hours

Figure I Schematic illustration of the green synthesis of Ag-nanoparticles-plant extract using aqueous extract of Pulicaria glutinosa plant. Abbreviations: T, temperature; t, time; NPs, nanoparticles; Aq, aqueous; soln, solution. 
In our continued research on Saudi Arabian plants for the development of valuable products with potential economic value, ${ }^{37-39}$ in the present study, we investigated the effect of $P$. glutinosa PEs on the antimicrobial activities of the silver NPs. The silver NPs (Ag-NPs-PE) were synthesized using different concentrations of PE as bioreductant. Antibacterial activities of capped silver NPs against Gramnegative (Escherichia coli, Pseudomonas aeruginosa) and Gram-positive (Staphylococcus aureus, Micrococcus luteus) bacteria were determined.

\section{Materials}

The whole plant of wild-growing $P$. glutinosa was collected from the hilly area of Al-Hair, central Saudi Arabia, in March 2011. Identification of plant material was confirmed by a plant taxonomist from the Herbarium Division, College of Science, King Saud University, Riyadh, Saudi Arabia. A voucher specimen has been deposited in our laboratory, as well as in the herbarium division of King Saud University (voucher specimen no. KSU-21598). Silver nitrate $\left(\mathrm{AgNO}_{3} ; 99.8 \%\right)$ was purchased from Sigma-Aldrich Co. (St Louis, MO, USA).

\section{Preparation of PEs}

The aerial parts from freshly collected plant material of $P$. glutinosa were chopped into small pieces. Chopped fresh aerial parts $(245.0 \mathrm{~g})$ were soaked in deionized water $(2,500 \mathrm{~mL})$ and refluxed for 3 hours. The aqueous solution obtained after reflux was filtered and dried at $50^{\circ} \mathrm{C}$ under reduced pressure in a rotary evaporator to give $17.2 \mathrm{~g}$ of dark brownish color powder; $0.1 \mathrm{~g} / \mathrm{mL}$ of this powdery extract was used for the synthesis of silver NPs.

\section{Synthesis of silver NPs}

In a typical experiment, the reaction mixture was prepared by adding $1.0 \mathrm{~mL}$ of the PEs to $99.0 \mathrm{~mL}$ of $1.0 \mathrm{mM}$ $\mathrm{AgNO}_{3}(169.87 \mathrm{mg})$ solution in a $250 \mathrm{~mL}$ round-bottom flask, which was mounted with a cooling condenser and magnetic stirring bar. The mixture was allowed to stir for 2.0 hours at $90^{\circ} \mathrm{C}$ (immediate color change was observed from light yellow to dark brown; thereafter, no further color change was observed, even after 2.0 hours). Afterward, the mixture was allowed to cool down, followed by centrifugation. The black powder obtained was washed with distilled water and then dried overnight in an oven at $80^{\circ} \mathrm{C}$.

To elucidate the effect of concentration of PE, various experiments were carried out by mixing 1.0, 2.5, 5.0, 7.5, and $10.0 \mathrm{~mL}$ aqueous solutions of $\mathrm{PE}$ and $1.0 \mathrm{mmol}$ of
$\mathrm{AgNO}_{3}(169.87 \mathrm{mg})$ in a respective amount of milli-Q water to make a total volume of $100 \mathrm{~mL}$.

\section{Characterization of NPs}

\section{Ultraviolet (UV)/visual spectroscopy}

A Perkin Elmer lambda 35 (Waltham, MA, USA) UV-visual spectrophotometer was used to conduct optical measurements. The analysis was performed in quartz cuvettes, using distilled water as a reference solvent. The samples for the UV measurements of crude mixture were prepared by diluting $1.0 \mathrm{~mL}$ mixture (collected at the end of reaction) in $9.0 \mathrm{~mL}$ water, sonicated for 15 minutes. The UV samples were prepared by diluting $2.0 \mathrm{~mL}$ stock solution of Ag-NPs-PE in $8.0 \mathrm{~mL}$ water. The stock solutions were prepared by dispersing $5.0 \mathrm{mg}$ Ag-NPs-PE in $5.0 \mathrm{~mL}$ water, followed by 1.0 hour sonication.

\section{Transmission electron microscopy}

Transmission electron microscopy was performed on a JEM 1101 (JEOL, Tokyo, Japan) transmission electron microscope. The samples for transmission electron microscopy were prepared by placing a drop of primary sample on a copper grid, which was then dried for 6.0 hours in an oven at $80^{\circ} \mathrm{C}$.

\section{Fourier transform infrared spectrometry}

Fourier transform infrared spectrometry spectra were measured on a Perkin-Elmer 1000 Fourier transforms infrared spectrometer. To remove any free biomass residue or unbound extract from the surfaces of NPs, Ag-NPs-PE were repeatedly washed with distilled water; subsequently, the product was centrifuged at 16,330 rcf for 30 minutes and dried. The purified Ag-NPs-PE were mixed with KBr powder and pressed into a pellet for measurement. Background correction was made using a reference blank $\mathrm{KBr}$ pellet.

\section{Bacterial strains}

E. coli, $P$. aeruginosa, M. luteus, and S. aureus were grown on autoclaved Luria broth, nutrient broth, Mueller-Hinton broth, and brain heart infusion broth, respectively. Strains were maintained on agar plates of their respective medium and were stored at $-80^{\circ} \mathrm{C}$ in $20 \%$ glycerol for long-term preservation.

\section{Antimicrobial activity of Ag-NPs-PE employing optical density}

The effect of PE capped Ag-NPs-PE, and that of the PE alone, on the growth of E. coli, P. aeruginosa, S. aureus, and $M$. luteus was determined by measuring the optical density 
(OD) of treated and untreated bacterium. Cells of E. coli, $P$. aeruginosa, $M$. luteus, and $S$. aureus from advanced logarithmic growth phase were inoculated $(20.0 \mu \mathrm{L})$ in $200 \mu \mathrm{L}$ autoclaved Luria broth, nutrient broth, Mueller-Hinton broth, and brain heart infusion broth. Ag-NPs-PE prepared with different concentrations of PE (ie, 1.0, 2.5, 5.0, 7.5, and $10.0 \mathrm{~mL}$ ) were added to the wells in triplicate to a final concentration of 50, 100, 200, 300, and $500 \mu \mathrm{g} / \mathrm{mL}$. Effects of PE were tested by adding the same concentration of $\operatorname{PE}(50,100,200,300$, and $500 \mu \mathrm{g} / \mathrm{mL})$ to culture media. Microtiter plates were incubated at $37^{\circ} \mathrm{C}$ on a rotary shaker at $140 \mathrm{rpm}$ for 8.0 hours. Absorbance was measured at $600 \mathrm{~nm}$ using an enzyme-linked immunosorbent assay reader (Multiskan Ascent, Labsystems, Helsinki, Finland) at hourly intervals.

Change in OD of a sample measured at a wavelength of $600 \mathrm{~nm}\left(\mathrm{OD}_{600}\right)$ was calculated by subtracting the $\mathrm{OD}_{600}$ at 0 hours from the $\mathrm{OD}_{600}$ at a given time. Results presented are the mean \pm standard error of three independent experiments each. $P$-values were calculated using an unpaired Student's $t$ test of GraphPad software (GraphPad Software, Inc., La Jolla, CA, USA). $P$-values considered significant for different tests are mentioned in the Figure captions.

\section{Half maximal inhibitory concentration values of Ag-NPs-PE}

Half maximal inhibitory concentration $\left(\mathrm{IC}_{50}\right)$ values of Ag-NPs-PE against E. coli, P. aeruginosa, S. aureus, and M. luteus were determined as follows: Cells of the tested organism were grown to logarithmic phase in the suitable medium, as described earlier. Aliquots of $500 \mu \mathrm{L}$ from these cultures of E. coli, P. aeruginosa, S. aureus, and M. luteus were inoculated in $5 \mathrm{~mL}$ autoclaved Luria broth, nutrient broth, Mueller-Hinton broth, and brain heart infusion broth, respectively. Ag-NPs-PE prepared with 1.0, 2.5, and $7.5 \mathrm{~mL}$ PE were added to final concentrations of 15,30 , and $60 \mu \mathrm{g} / \mathrm{mL}$. Tubes were incubated overnight in a rotary shaker at $37^{\circ} \mathrm{C}$. After incubation, appropriate dilutions of samples adjusted with various concentrations of Ag-NPs-PE and unadjusted samples were made in autoclaved phosphate-buffered saline ( $\mathrm{pH}, 7.0)$. An aliquot of $100 \mu \mathrm{L}$ from the appropriate dilution was spread on an agar plate of the respective medium, and plates were incubated at $37^{\circ} \mathrm{C}$ for 48 hours. After incubation, colony-forming units were determined and plotted using Sigma plot (Systat Software Inc, London, UK). Values presented are mean and standard deviation of three values. $\mathrm{IC}_{50}$ values were also calculated using Sigma plot.

\section{Results and discussion}

P. glutinosa PE was used for the synthesis of silver NPs under facile conditions (Figure 1). ${ }^{37}$ It was observed that on the addition of PE into the aqueous solution of $\mathrm{AgNO}_{3}$, the color of the solution gradually changed from light yellow to dark brown, indicating the formation of silver NPs (Figure 2B). ${ }^{37}$ The formation of the as-prepared AgNPs-PE was initially monitored by UV-visual analysis. Typically, Ag-NPs-PE exhibit absorption under a visible range of 380-450 nm, depending on the shape and size of the NPs. ${ }^{40}$ Figure 2 shows the absorption spectrum of AgNPs-PE that were prepared at $90^{\circ} \mathrm{C}$ (Figure 2A).

In our earlier studies, the detailed investigation of the effect of concentration of the P. glutinosa PE on the synthesis of Ag-NPs-PE was evaluated using UV/visual spectroscopy. ${ }^{37}$ During the analysis, it was observed that the concentration of the PE exerts a significant effect on

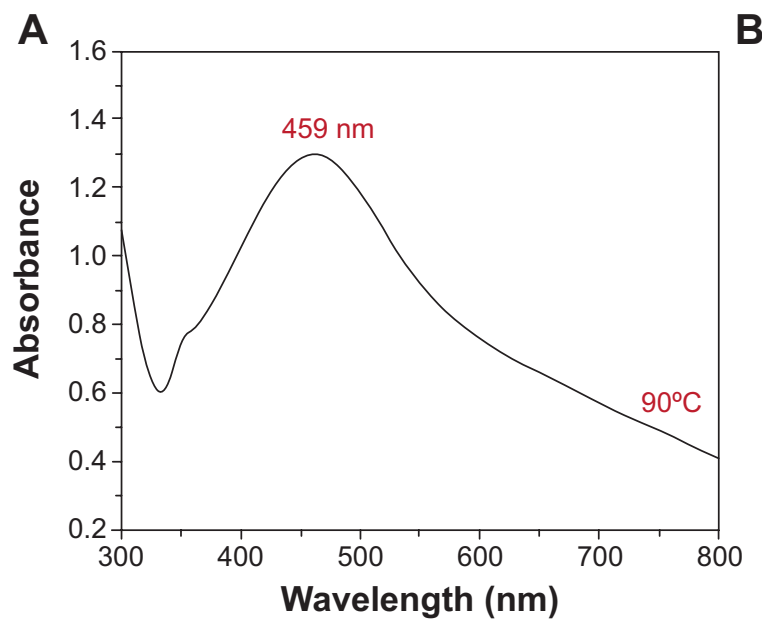

B

Figure 2 (A) Ultraviolet-visual absorption spectrum of Ag-nanoparticles-plant extract prepared at $90^{\circ} \mathrm{C}$. (B) Digital photograph of the aqueous solutions of (i) $\mathrm{AgNO}_{3}$ solution without addition of plant extract. (ii) $\mathrm{AgNO}_{3}$ with the addition of plant extract and pure plant extract solution with $0.1 \mathrm{~g} / \mathrm{mL}$ concentration. i and ii were recorded after 72 hours. 
the size and distribution of NPs. The quantity of the PE was varied from 1.0 to $10.0 \mathrm{~mL}$, keeping other conditions


concentration of the PE, both the position and shape of the surface plasmon resonance bands varied.

Initially, as the quantity of the PE is varied from 1.0 to $5.0 \mathrm{~mL}$, it was found that the surface plasmon resonance bands were blue shifted from 455 to $422 \mathrm{~nm}$, with a simultaneous increase in the absorption coefficient, whereas with further increase in the concentration (up to $10 \mathrm{~mL}$ ), the bands became sharper and shifted to longer wavelength (ie, from $422-459 \mathrm{~nm}$; Figure 3A). The sharpness of the absorption band with the increase of PE concentration is attributed to the better stabilization of NPs surfaces. The NPs were stabilized by the binding of organic compounds present in the PEs, which also act as surface-functionalizing ligands to the surfaces of the NPs. ${ }^{37}$ It has been suggested that at the higher concentration of $\mathrm{PE}$, a greater number of functional ligands may bind to the surfaces of the NPs and provide better stabilization to the NPs. This was also reflected by the color change of the diluted solution of pure Ag-NPs-PE from light brown to dark brown with an increasing concentration of PE (Figure 3B).

The transmission electron microscopy images of the as-prepared silver NPs revealed the spherical morphology of NPs, with a size range of 40-60 nm, in which few NPs were agglomerated (Figure 4A-D). These results also suggest that the agglomeration of NPs decreases when increasing the concentration of the PE, which is also evident in the UV results. ${ }^{37}$

Furthermore, the dual role of the PE, both as a bioreductant and as a capping agent, has also been confirmed by the Fourier transform infrared spectrometry analysis of the as-prepared Ag-NPs-PE (Figure 5). The similarities between both spectra, with some marginal shifts in peak position, clearly suggest the presence of residual PE in the sample as capping agent to the Ag-NPs-PE. The detailed analysis of the spectra of PEs strongly suggested the presence of flavonoids and polyphenols, apart from other phytochemicals, which were mainly responsible for the formation of Ag-NPs-PE by reducing $\mathrm{AgNO}_{3} \cdot{ }^{37}$

\section{Antimicrobial activity}

The silver NPs synthesized using P. glutinosa extract (AgNPs-PE) were evaluated for their antimicrobial activity against E. coli, P. aeruginosa, S. aureus, and M. luteus, using two different methods.

\section{Evaluation of antimicrobial activity of Ag-NPs-PE employing OD}

Preliminary results on growth inhibition were obtained by determining the $\mathrm{OD}_{600}$ of bacteria grown with various concentrations of Ag-NPs-PE $(50-500 \mu \mathrm{g} / \mathrm{mL})$. Initially, we measured the antibacterial activity of PE against four bacterial strains, as shown in Figure 6A-D, which illustrates PE antibacterial activity against both Gram-negative and Gram-positive bacteria. It is clear from the Figures that the extracts from $P$. glutinosa do not inhibit the growth of the tested bacteria, even at the highest tested concentration (50-500 $\mu \mathrm{g} / \mathrm{mL}$ ). Therefore, it can be concluded from the data presented in Figure 6 that the extract of P. glutinosa does not have toxicity of its own.

\section{Gram-negative bacterial strains}

Thereafter, the antibacterial activity of PE capped silver NPs prepared with various concentrations was measured against

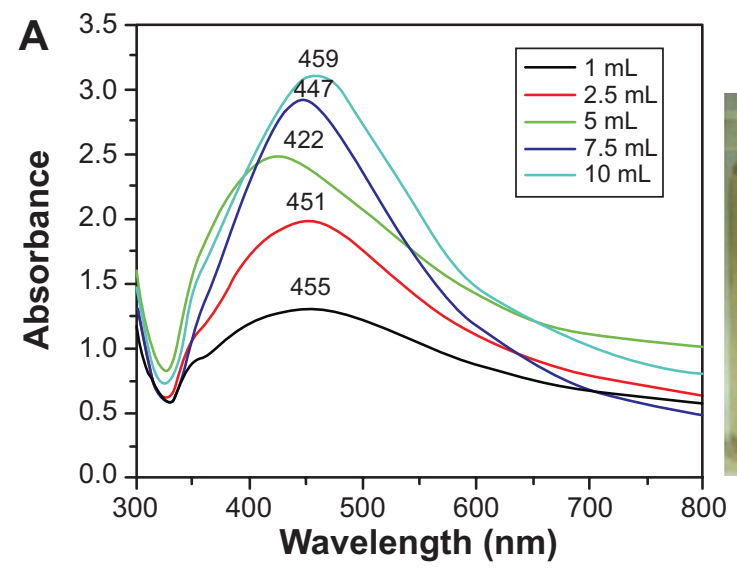

B

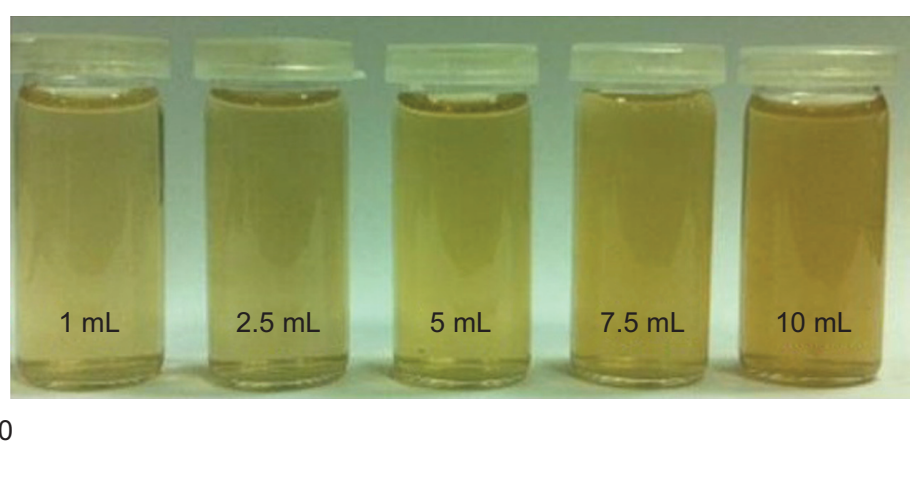

Figure 3 Ultraviolet-visual absorption spectra of Ag-nanoparticles-plant extract prepared at $90^{\circ} \mathrm{C}$ for 2 hours (A), using various concentrations of plant extract keeping the amount of $\mathrm{AgNO}_{3}$ constant (ie, $1.0 \mathrm{mmol}$ ). (B) The diluted solutions of pure Ag-nanoparticles-plant extract (obtained after final workup). 

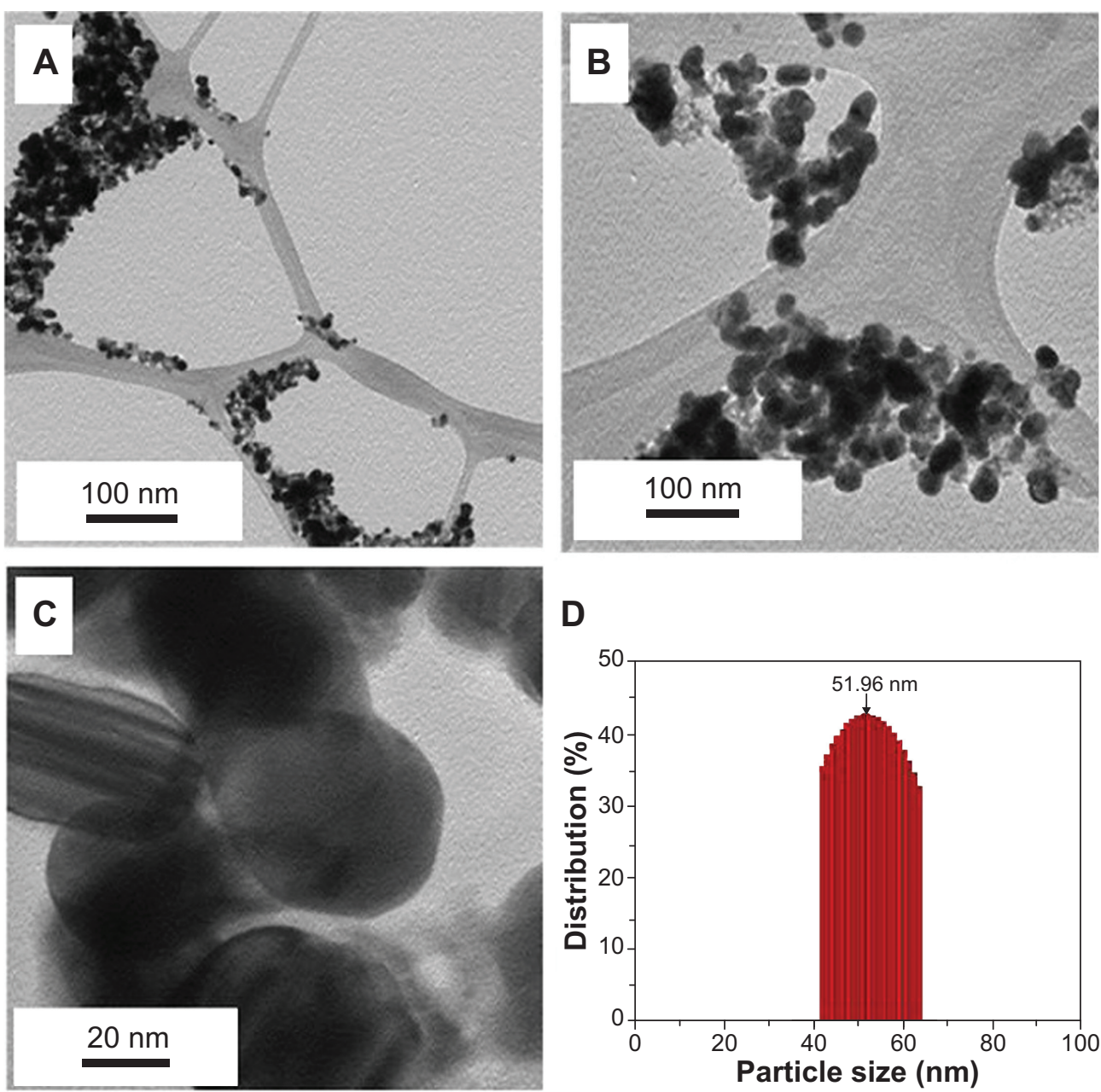

Figure $4(\mathbf{A}-\mathbf{C})$ Transmission electron microscope images of the green synthesized silver nanoparticles at different scales. (D) Overview of the size range and distribution of the silver NPs.

Note: With increasing concentration, less agglomeration was observed.



Figure 5 Fourier-transform infrared spectra of pure green synthesized silver nanoparticles (Ag-nanoparticles-plant extract) (line $\mathbf{A})$ and Pulicaria glutinosa plant extract (line B).

Note: The similarities between the spectra strongly suggest the presence of plant extract residue in the Ag-nanoparticles-plant extract as a capping or stabilizing agent.
E. coli. The effect of various concentrations of capped AgNPs-PE (50-500 $\mu \mathrm{g} / \mathrm{mL})$, prepared with 1.0, 2.5, 5.0, 7.5, and $10.0 \mathrm{~mL} \mathrm{PE}$ on the growth of $E$. coli, is shown in Figure 7A-F. Similarly, the antibacterial activities of PE capped silver NPs have also been measured against other bacterial strains, including $P$. aeruginosa, M. luteus, and $S$. aureus, for which the Figures are provided in the supplementary information (Figures S1, S2, and S3, respectively). From the results presented in Figure 7 and Figures S1-S3, it was observed that a concentration of $50 \mu \mathrm{g} / \mathrm{mL}$ was optimal to determine the effect of the addition of PE on the antimicrobial property of Ag-NPs-PE. Figure 8 summarizes the effect of the PE concentration (1.0, 2.5, 5.0, 7.5, and $10.0 \mathrm{~mL})$ on the antimicrobial activity of $50 \mu \mathrm{g} / \mathrm{mL}$ Ag-NPs-PE against E. coli, P. aeruginosa, M. luteus, and S. aureus.

The results presented in Figure 7 suggest that as the concentration of PE used for the synthesis of Ag-NPs-PE increased from 1.0 to $7.5 \mathrm{~mL}$, the growth of E. coli in 

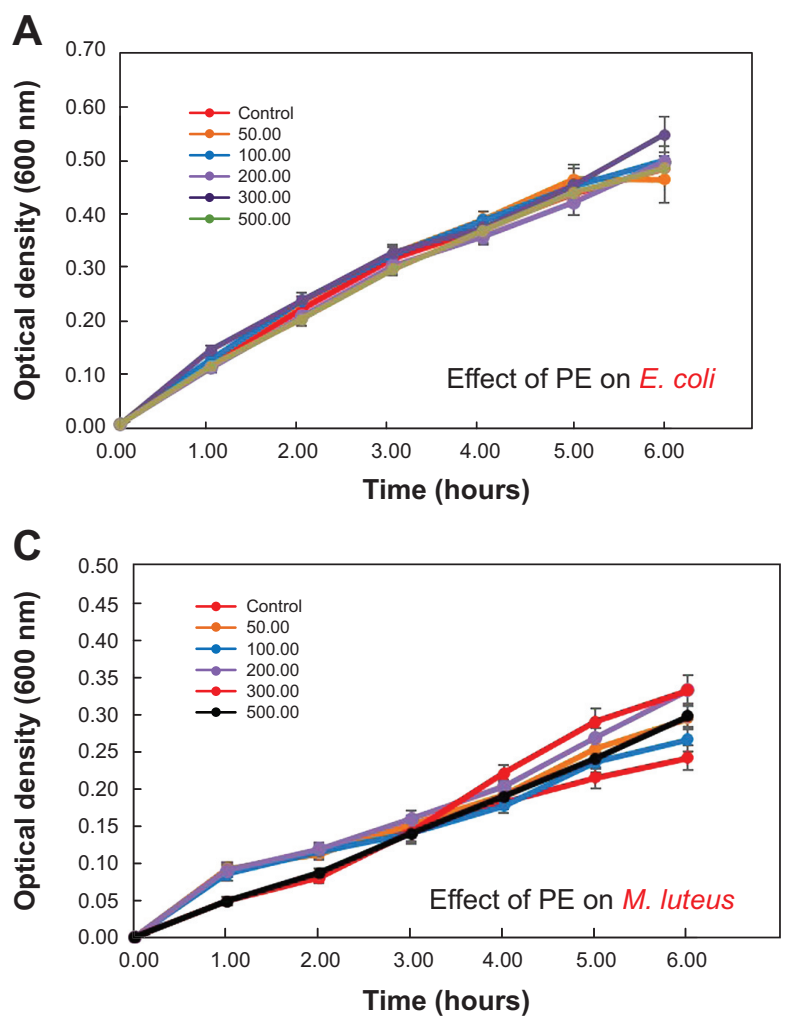
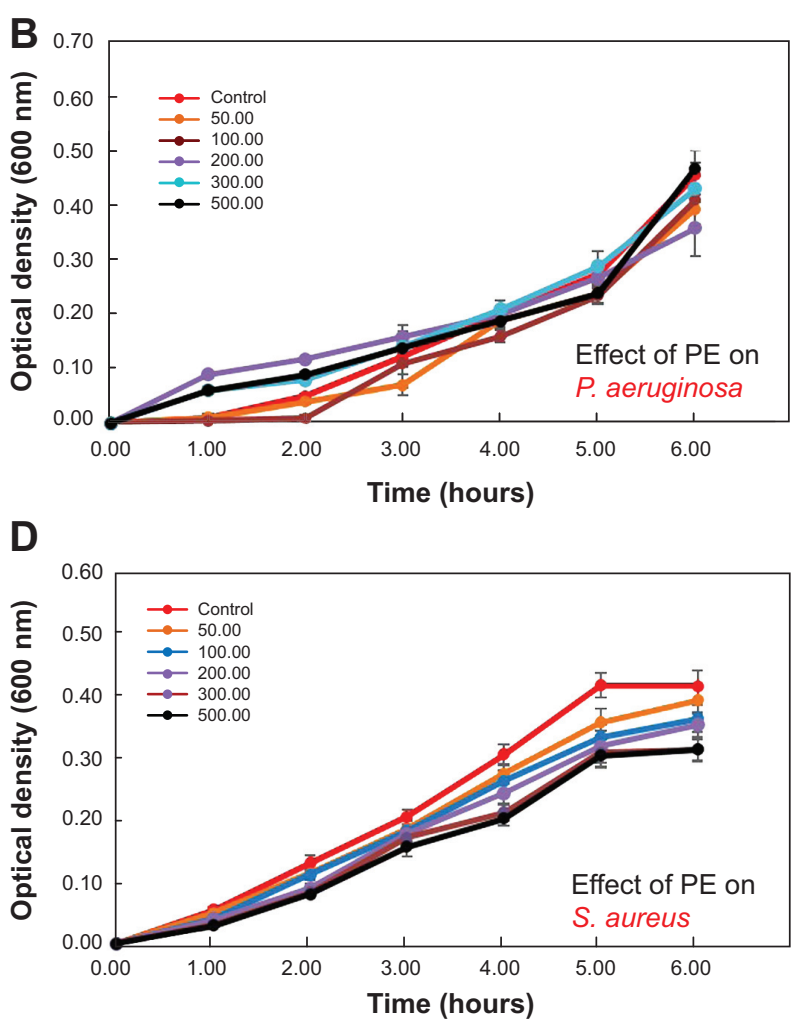

Figure 6 Antibacterial activity of Pulicaria glutinosa plant extract against both Gram-negative ([A] Escherichia coli [B] Pseudomonas aeruginosa) and Gram-positive ([C] Micrococcus luteus and [D] Staphylococcus aureus) bacteria.

Note: The plant extracts do not show any antibacterial activity against the tested strains.

Abbreviation: PE, plant extract.

terms of $\mathrm{OD}_{600}$ values decreased from $22 \%$ to $61 \%$, and a similar decrease in $\mathrm{OD}_{600}$ from $20 \%$ to $60 \%$ was observed for $P$. aeruginosa (Figure $\mathrm{S} 1$ ). This can be attributed to the better stabilization of NPs and their surface functionalization, with phytomolecules present in the PE. When the PE concentration used for the synthesis of Ag-NPs-PE was increased further from 7.5 to $10.0 \mathrm{~mL}$, the antimicrobial activity of the Ag-NPs-PE decreased sharply against both the bacteria (ie, E. coli and $P$. aeruginosa compared with the values obtained at $7.5 \mathrm{~mL}$; Figure 7 and Figure S1). This decrease in activity can be ascribed to the agglomeration of NPs, leading to the formation of large-size NPs, which ultimately reduces the surface area of the NPs, thus resulting in poor interaction of the NPs with the bacterial cell, because of which, the antibacterial activity of the NPs was decreased significantly.

\section{Gram-positive bacterial strains}

In addition to Gram-negative bacteria, the antimicrobial activity of the capped Ag-NPs-PE was also tested against Gram-positive bacterial strains such as M. luteus and $S$. aureus. Notably, slight growth inhibition was observed in the case of $M$. luteus, whereas almost no growth inhibition was observed in cases of $S$. aureus. As shown in Figures S2 and S3, the growth of $M$. luteus was slightly inhibited at $50 \mu \mathrm{g} / \mathrm{mL}$, and at higher concentrations of Ag-NPs-PE, it was found to be highly toxic, as was observed in the case of Gram-negative bacterial strains (E. coli and P. aeruginosa). On observation, Figure S2F appears to be similar to Figure $7 \mathrm{~F}$ and Figure S1F in terms of percentage growth inhibition, but in terms of the $\mathrm{OD}_{600}$ values obtained for $M$. luteus, the growth inhibition is not significant. In the case of $S$. aureus, nil to negligible growth inhibition was exhibited by the Ag-NPs-PE at tested concentrations, as shown in Figure $\mathrm{S} 3 \mathrm{~A}-\mathrm{F}$.

Figure $8 \mathrm{~A}-\mathrm{D}$ summarizes the effect of the concentration of PE (1.0, 2.5, 5.0, 7.5, and $10.0 \mathrm{~mL})$ used to synthesize $50 \mu \mathrm{g} / \mathrm{mL}$ Ag-NPs-PE on the growth of four organisms tested. From the results, it is evident that the PEs obtained from $P$. glutinosa do not exhibit any antimicrobial activity against Gram-positive and Gram-negative bacterial strains tested in this study, up to a concentration of $500 \mu \mathrm{g} / \mathrm{mL}$. Although, the toxicity/antimicrobial activity of Ag-NPs-PE $(50 \mu \mathrm{g} / \mathrm{mL})$ increased with increasing concentration of plant extracts used in their preparation, which can be a result of the increased solubility of the Ag-NPs-PE. Moreover, the antimicrobial activity of Ag-NPs-PE was observed only against Gram-negative bacteria, namely, E. coli and $P$. aeruginosa, 
A
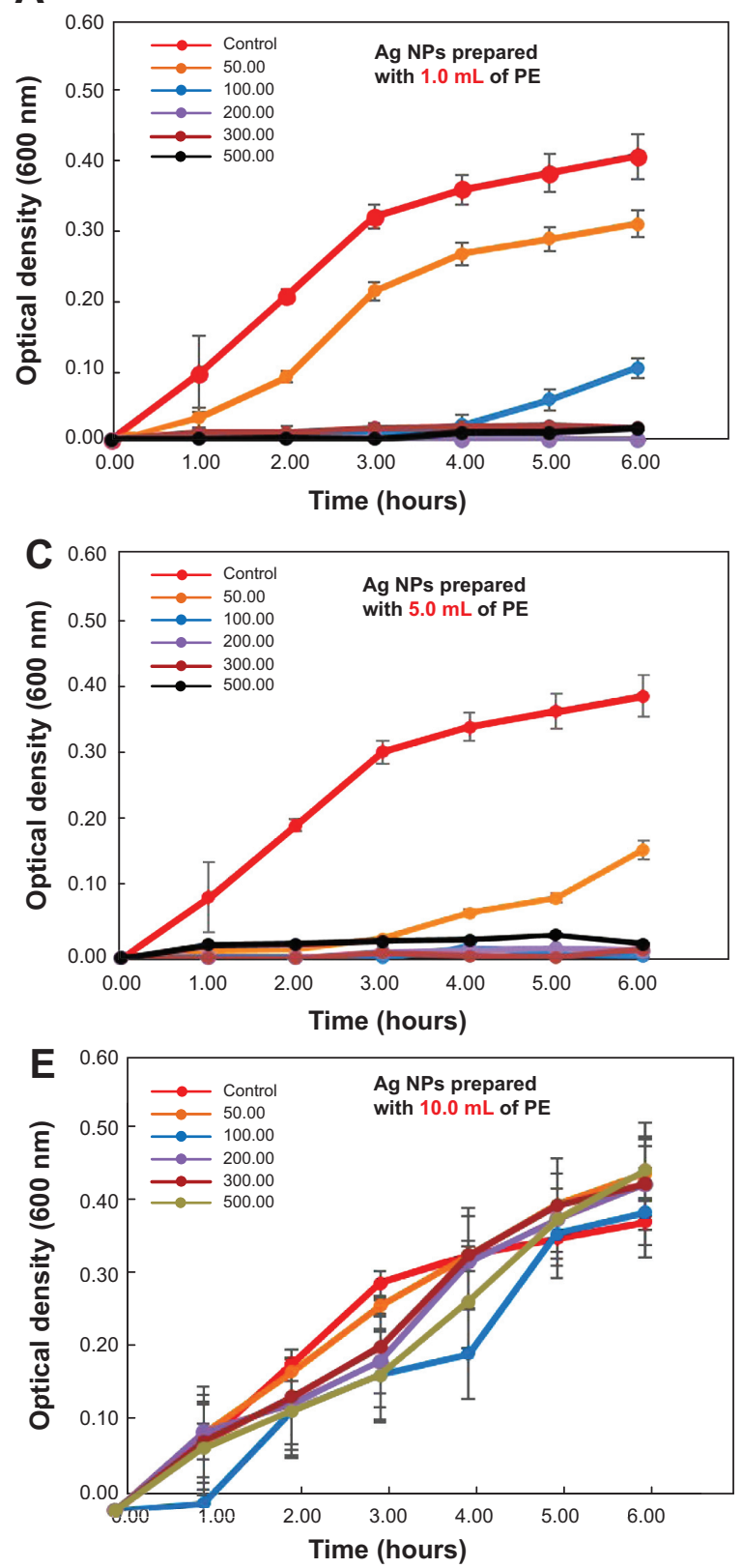

B
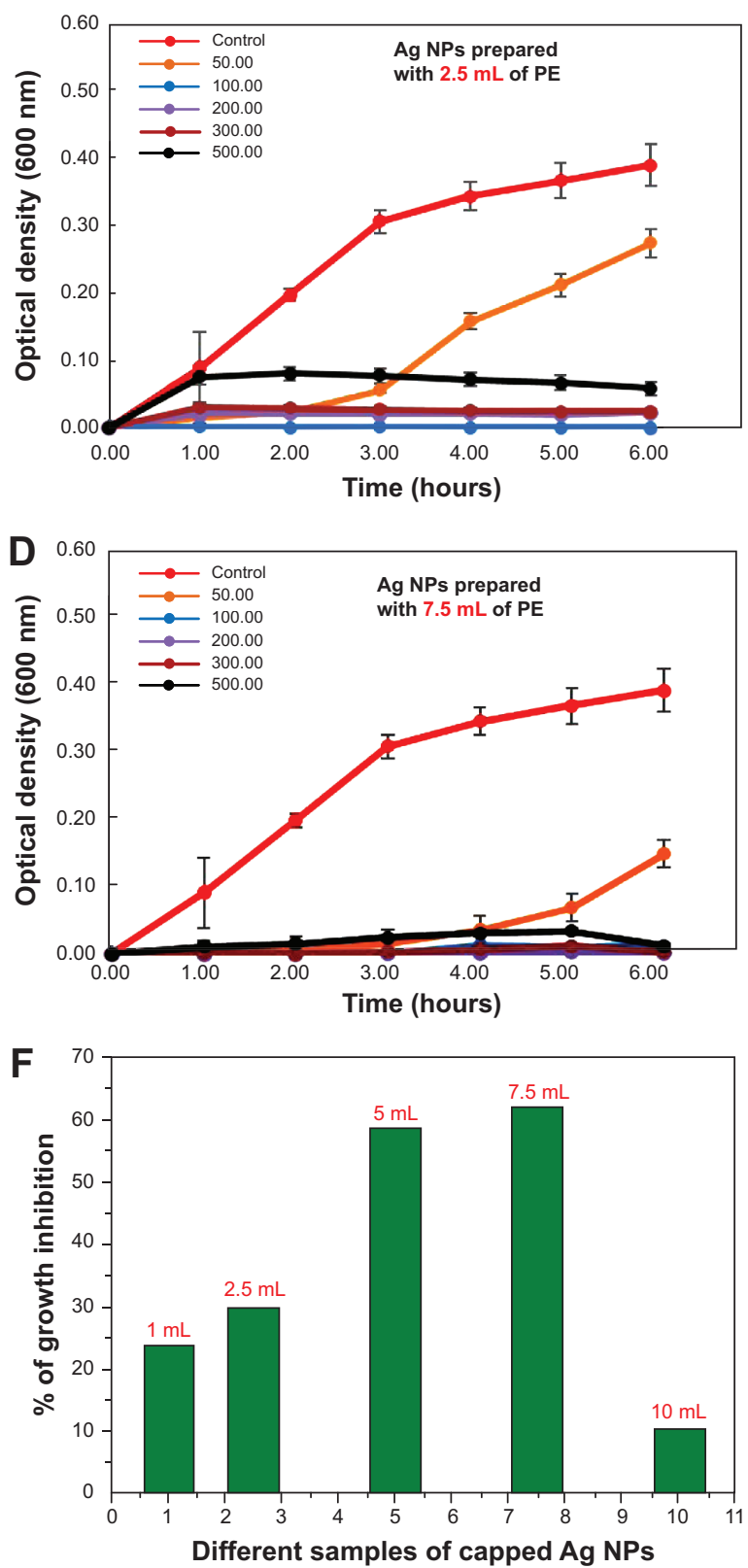

Figure 7 Effect of various concentrations of capped Ag-nanoparticles (NPs)-plant extract (PE; 50-500 $\mu \mathrm{g} / \mathrm{mL})$ prepared with (A) I.0 mL, (B) $2.5 \mathrm{~mL}$, (C) $5.0 \mathrm{~mL}$, (D) $7.5 \mathrm{~mL}$, and $(E) 10.0 \mathrm{~mL}$ Pulicaria glutinosa extract on the growth of Escherichia coli (the activity is presented in terms of change in optical density of a sample measured at a wavelength of $600 \mathrm{~nm})$. (F) Percentage inhibition on growth of Escherichia coli resulting from the capped Ag-NPs-PE ( $50 \mu \mathrm{g} / \mathrm{mL})$, prepared with different concentrations of plant extract.

whereas almost no effect was observed against the tested Gram-positive bacterial strains M. luteus and S. aureus.

\section{Evaluation of antimicrobial activity} of Ag-NPs-PE employing colony forming unit (CFU) count methods (determination of $\mathrm{IC}_{50}$ value)

Gram-negative bacterial strains

Growth inhibition of bacterial strains with different concentrations of Ag-NPs-PE was checked as detailed in
Materials, using the CFU method. Figure 9 shows the effect of synthesized Ag-NPs-PE on the growth of E. coli (Figure 9A) and P. aeruginosa (Figure 9B) in terms of CFU counts. When a comparison was drawn between AgNPs-PE prepared with $7.5 \mathrm{~mL}$ and $1.0 \mathrm{~mL} \mathrm{PE}$, which were added to the medium to a final concentration of $15 \mu \mathrm{g} / \mathrm{mL}$, it was observed that there was a $20 \%$ decrease in CFU counts of E. coli in the plate with $7.5 \mathrm{~mL} \mathrm{PE}$ compared with the plate with $1.0 \mathrm{~mL}$. This effect was more prominent when Ag-NPs-PE were added to a final concentration 
A



C



B



D

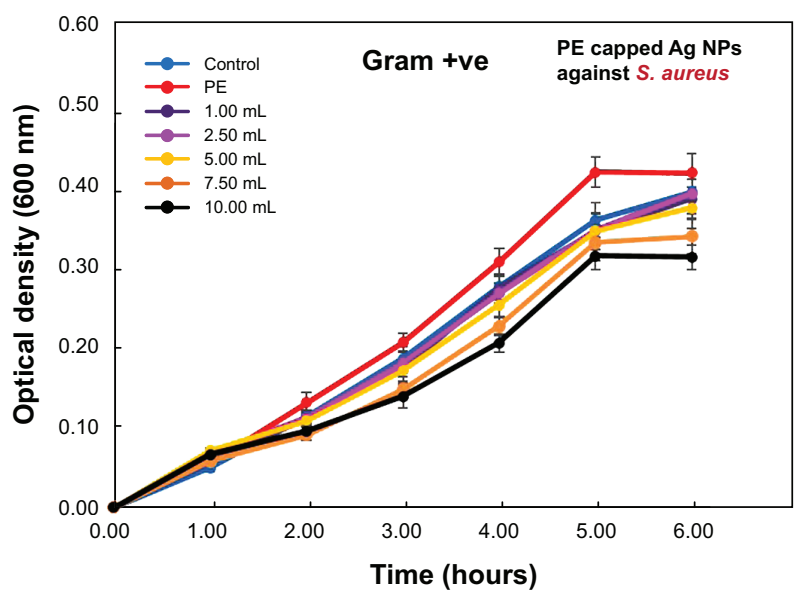

Figure 8 Antibacterial activities of capped Ag-nanoparticles (NPs)-plant extract (PE; $50 \mu \mathrm{g} / \mathrm{mL}$ ) prepared with various concentrations of the Pulicaria glutinous plant extracts $(\mathrm{I} .0,2.5,5.0,7.5$, and $10.0 \mathrm{~mL}$ ). (A) Effect of plant extract capped Ag-NPs-PE on the growth of Escherichia coli, (B) Pseudomonas aeruginosa, (C) Micrococcus luteus, and (D) Staphylococcus aureus. The antibacterial activities are shown in terms of change in optical density $(600 \mathrm{~nm})$.

Note: $* P<0.005$.

Abbreviations: -ve, negative; +ve, positive.
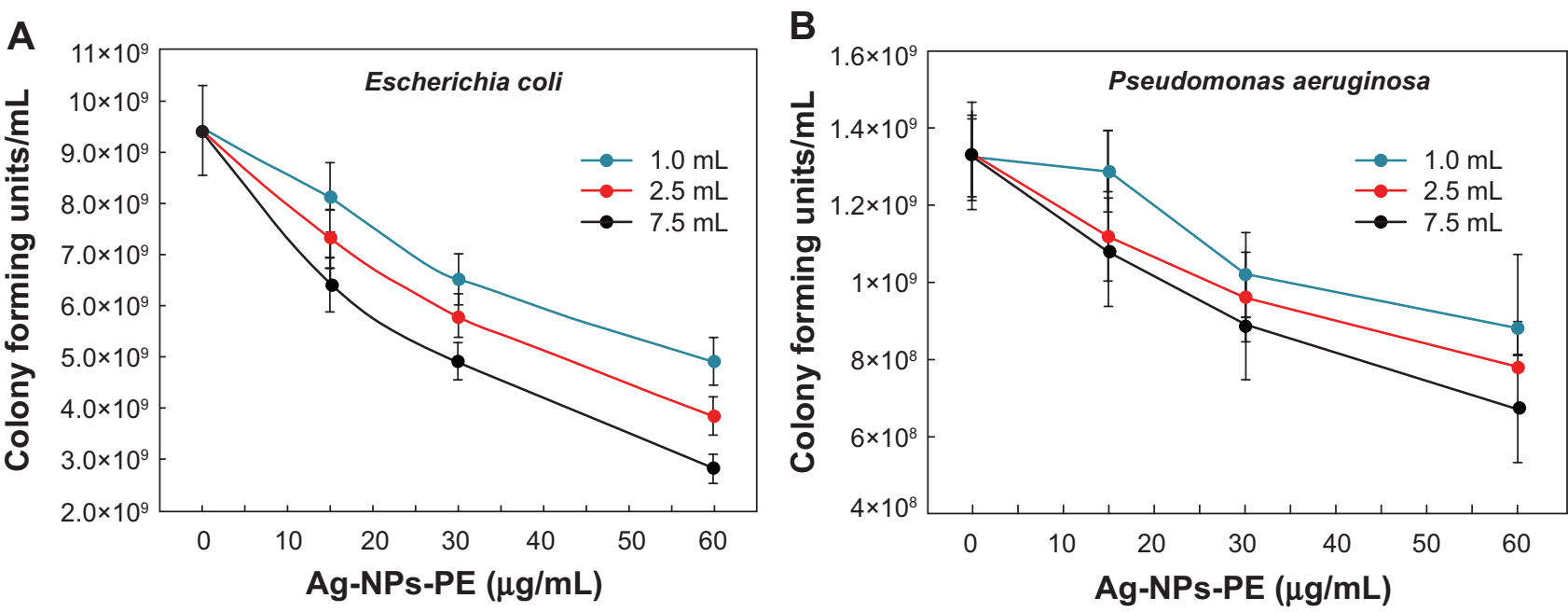

Figure 9 Colony-forming units of Gram-negative bacteria Escherichia coli (A) and Pseudomonas aeruginosa (B) obtained after treatment with various concentrations of Agnanoparticles (NPs)-plant extract (PE; 0, 15, 30, and $60 \mu \mathrm{g} / \mathrm{mL}$ ) synthesized with $1.0 \mathrm{~mL}$ (blue line), $2.5 \mathrm{~mL}$ (red line), and $7.5 \mathrm{~mL}$ (black line) PE. Values presented are mean and standard deviation of three values. 
of $60 \mu \mathrm{g} / \mathrm{mL}$, where the CFU counts decreased by $42 \%$. The $\mathrm{IC}_{50}$ value of Ag-NPs-PE synthesized with $1.0 \mathrm{~mL}$ of PE against $E$. coli was found to be $53 \mu \mathrm{g} / \mathrm{mL}$, whereas the $\mathrm{IC}_{50}$ of Ag-NPs-PE synthesized with 2.5 and $7.5 \mathrm{~mL}$ was found to be 47 and $43 \mu \mathrm{g} / \mathrm{mL}$, respectively. From the values obtained by these investigations, it can be said that the $\mathrm{IC}_{50}$ value decreases by $10 \%$ with the increase in use of PE concentration from 1.0 to $7.5 \mathrm{~mL}$ for the green synthesis of silver NPs. A similar trend was obtained for $P$. aeruginosa (Figure 9B). CFU counts decreased by a maximum of $24 \%$ when Ag-NPs-PE synthesized with $7.5 \mathrm{~mL}$ were added to a final concentration of $60 \mu \mathrm{g} / \mathrm{mL}$ compared with the same concentration of silver-NPs-PE synthesized with $1.0 \mathrm{~mL}$ PE. The $\mathrm{IC}_{50}$ value of Ag-NPs-PE synthesized with $1.0 \mathrm{~mL}$ PE against $P$. aeruginosa was found to be $42 \mu \mathrm{g} / \mathrm{mL}$, and there was a decrease in the $\mathrm{IC}_{50}$ values to 37 and $33 \mu \mathrm{g} / \mathrm{mL}$ when the concentration of PE used for the synthesis of Ag-NPs-PE increased to 2.5 and $7.5 \mathrm{~mL}$, respectively.

\section{Gram-positive bacterial strains}

The evaluation of antimicrobial activity of the synthesized Ag-NPs-PE was also carried out against Gram-positive bacterial strain M. luteus (Figure 10A). It was observed that the CFU counts decreased by only $4 \%$ when $15 \mu \mathrm{g} /$ $\mathrm{mL}$ Ag-NPs-PE synthesized with $7.5 \mathrm{~mL}$ PE was added to the medium compared with the Ag-NPs-PE prepared with $1.0 \mathrm{~mL}$ PE. A maximum 9\% decrease was observed when the Ag-NPs-PE prepared with $7.5 \mathrm{~mL}$ plant extract were added to a final concentration of $60 \mu \mathrm{g} / \mathrm{mL}$ compared with the same concentration of Ag-NPs-PE prepared with $1.0 \mathrm{~mL}$ PE. The $\mathrm{IC}_{50}$ values of Ag-NPs-PE prepared with 1.0 and $2.5 \mathrm{~mL}$
PE were found to be $95 \mu \mathrm{g} / \mathrm{mL}$ in both cases, whereas the $\mathrm{IC}_{50}$ value of Ag-NPs-PE prepared with $7.5 \mathrm{~mL}$ PE showed a slight decrease to $76 \mu \mathrm{g} / \mathrm{mL}$.

The Ag-NPs-PE were tested for their antibacterial property against another Gram-positive bacterial strain, S. aureus. Observations in the CFU counts revealed that with Ag-NPs-PE prepared with $7.5 \mathrm{~mL} \mathrm{PE}$ there is a maximum decrease of $3 \%$ compared with the same concentration of Ag-NPs-PE prepared with $1.0 \mathrm{~mL}$ PE (Figure 10B). The $\mathrm{IC}_{50}$ value of $\mathrm{Ag}-$ NPs-PE prepared with $1.0 \mathrm{~mL}$ PE was found to be $82 \mu \mathrm{g} / \mathrm{mL}$, whereas for those synthesized with 2.5 and $7.5 \mathrm{~mL}$, it was found to be 79 and $78 \mu \mathrm{g} / \mathrm{mL}$, respectively.

It can be elucidated from the data presented here that by employing both the OD and CFU counts, the methods delivered similar results of antibacterial activity trends against the bacterial strains tested. The concentration at which the effect of PE was clearly visible was $50 \mu \mathrm{g} / \mathrm{mL}$ of Ag-NPs-PE. Moreover, the effect was less visible at a concentration of $100 \mu \mathrm{g} / \mathrm{mL}$ and higher in OD-based experiments because the initial OD of NPs alone is higher at these concentrations. However, the toxicity of Ag-NPs-PE on different organisms was in the following order: E. coli $>$ P. aeruginosa $>$ $M$. luteus $>S$. aureus. $\mathrm{IC}_{50}$ values calculated using the plate count method of synthesized Ag-NPs-PE against Gram-positive bacteria were almost two times those of Gram-negative bacteria, which is similar to the results obtained from the OD experiments. Hence it can be stated that the synthesized Ag-NPs-PE are much more effective against Gram-negative bacteria than Gram-positive bacteria.

Notably, the antimicrobial activity of Ag-NPs-PE against $E$. coli has been widely reported; however, the reports on


Figure 10 Colony-forming units of Gram-positive bacteria Micrococcus luteus (A) and Staphylococcus aureus (B) obtained after treatment with various concentrations of Ag-nanoparticles (NPs)-plant extract (PE; 0, 15, 30, and $60 \mu \mathrm{g} / \mathrm{mL}$ ) synthesized with $1.0 \mathrm{~mL}$ (blue line), $2.5 \mathrm{~mL}$ (red line), and $7.5 \mathrm{~mL}$ (black line) of PE. Note: Values presented are mean and standard deviation of three values. 
the antimicrobial activity against $S$. aureus are variable, with some claiming excellent activities of Ag-NPs-PE against $S$. aureus, whereas others reported nil or negligible activity against the same bacterial strain. ${ }^{41,42}$ This could be a result of the different shapes of Ag-NPs-PE yielding from different synthetic procedures. ${ }^{20,43}$ For instance, the study carried out by Pal et al demonstrates that the antimicrobial activity of silver NPs against bacterial strains is shape-dependent. ${ }^{24}$ Similar findings were reported by Premanathan et al regarding the toxicity of ZnO NPs against Gram-positive bacteria, which suggests that the shapeselective activity of NPs against bacterial strains can be found for other NPs too. ${ }^{44}$

\section{Conclusion}

Here we have clearly and successfully demonstrated that the green approach to the synthesis of silver NPs employing PE of P. glutinosa led to the formation of silver NPs with increased solubility and enhanced antimicrobial activity. Although the PE of $P$. glutinosa does not possess antibacterial activity of its own, it has significant effects on the antimicrobial property of silver NPs. It can be concluded that the PE of $P$. glutinosa facilitates and controls the stabilization and size of the silver NPs, because of which, the interaction between NPs and bacterial cell wall increases significantly, resulting in enhanced antibacterial activity of PE capped silver NPs (AgNPs-PE). Furthermore, the enhanced antibacterial activity of PE capped silver NPs have been confirmed with two different methods, including OD and CFU counts' methods, and the results of both methods have consistently suggested higher toxicity to Gram-positive bacteria than to Gram-negative bacteria. Therefore, green synthesis of NPs will help in developing ecofriendly and cheap antimicrobial agents as an alternate to conventionally used antimicrobial agents. Further research in this area therefore is highly warranted.

\section{Acknowledgment}

This project was supported by King Saud University, Deanship of Scientific Research, College of Science, Research Center.

\section{Disclosure}

The authors report no conflicts of interest in this work.

\section{References}

1. Riley MA, Robinson SM, Roy CM, Dennis M, Liu V, Dorit RL. Resistance is futile: the bacteriocin model for addressing the antibiotic resistance challenge. Biochem Soc Trans. 2012;40(6):1438-1442.

2. Stanton TB. A call for antibiotic alternatives research. Trends Microbiol. 2013;21(3):111-113.
3. Moellering RC Jr. Discovering new antimicrobial agents. Int $J$ Antimicrob Agents. 2011;37(1):2-9.

4. Doyle MP, Loneragan GH, Scott HM, Singer RS. Antimicrobial resistance: Challenges and perspectives. Compr Rev Food Sci Food Saf. 2013; 12:234-248.

5. Hajipour MJ, Fromm KM, Ashkarran AA, et al. Antibacterial properties of nanoparticles. Trends Biotechnol. 2012;30(10):499-511.

6. Singh R, Nalwa HS. Medical applications of nanoparticles in biological imaging, cell labeling, antimicrobial agents, and anticancer nanodrugs. J Biomed Nanotechnol. 2011;7(4):489-503.

7. Botequim D, Maia J, Lino MM, et al. Nanoparticles and surfaces presenting antifungal, antibacterial and antiviral properties. Langmuir. 2012;28(20):7646-7656.

8. Xia Y. Nanomaterials at work in biomedical research. Nat Mater. 2008;7(10):758-760.

9. Doane TL, Burda C. The unique role of nanoparticles in nanomedicine: imaging, drug delivery and therapy. Chem Soc Rev. 2012;41(7): 2885-2911.

10. Khan ST, Ahamed M, Alhadlaq HA, Musarrat J, Al-Khedhairy A. Comparative effectiveness of $\mathrm{NiCl}_{2}, \mathrm{Ni}$ - and $\mathrm{NiO}-\mathrm{NPs}$ in controlling oral bacterial growth and biofilm formation on oral surfaces. Arch Oral Biol. 2013;58(12):1804-1811.

11. Chowdhury MNK, Beg MDH, Khan MR, Mina MF. Synthesis of copper nanoparticles and their antimicrobial performances in natural fibres. Mater Lett. 2012;112:841-852.

12. Khan ST, Ahmad M, Al-Khedhairy AA, Musarrat J. Biocidal effect of copper and zinc oxide nanoparticles on human oral microbiome and biofilm formation. Mater Lett. 2013;97:67-70.

13. Perelshtein I, Ruderman E, Perkas N, et al. Chitosan and chitosan-ZnO based complex nanoparticles: formation, characterization and antibacterial activity. J Mater Chem B. 2013;1(14):1968-1976.

14. Seltenrich N. Nanosilver: weighing the risks and benefits. Environ Health Perspect. 2013;121(7):A220-A225.

15. Rai MK, Deshmukh SD, Ingle AP, Gade AK. Silver nanoparticles: the powerful nanoweapon against multidrug-resistant bacteria. $J$ Appl Microbiol. 2012;112(5):841-852.

16. Rai M, Yadav A, Gade A. Silver nanoparticles as a new generation of antimicrobials. Biotechnol Adv. 2009;27(1):76-83.

17. Morones JR, Elechiguerra JL, Camacho A, et al. The bactericidal effect of silver nanoparticles. Nanotechnology. 2005;16(10):2346-2353.

18. Liu JL, Luo Z, Bashir S. A progressive approach on inactivation of bacteria using silver-titania nanoparticles. Biomater Sci. 2013;1:194-201.

19. Feng QL, Wu J, Chen GQ, Cui FZ, Kim TN, Kim JO. A mechanistic study of the antibacterial effect of silver ions on Escherichia coli and Staphylococcus aureus. J Biomed Mater Res. 2000;52(4):662-668.

20. Xiu ZM, Zhang QB, Puppala HL, Colvin VL, Alvarez PJ. Negligible particle-specific antibacterial activity of silver nanoparticles. Nano Lett. 2012;12(8):4271-4275.

21. Taglietti A, Diaz Fernandez YA, Amato E, et al. Antibacterial activity of glutathione-coated silver nanoparticles against Gram positive and Gram negative bacteria. Langmuir. 2012;28(21):8140-8148.

22. Priyaragini S, Sathishkumar SR, Bhaskararao KV. Biosynthesis of silver nanoparticles using actinobacteria and evaluating its antimicrobial and cytotoxicity activity. Int J Pharm Pharm Sci. 2013;5(2):709-712.

23. Kim TH, Kim M, Park HS, Shin US, Gong MS, Kim HW. Sizedependent cellular toxicity of silver nanoparticles. J Biomed Mater Res A. 2012;100(4):1033-1043.

24. Pal S, Tak YK, Song JM. Does the antibacterial activity of silver nanoparticles depend on the shape of the nanoparticle? A study of the Gram-negative bacterium Escherichia coli. Appl Environ Microbiol. 2007;73(6):1712-1720.

25. El Badawy AM, Silva RG, Morris B, Scheckel KG, Suidan MT, Tolaymat TM. Surface charge-dependent toxicity of silver nanoparticles. Environ Sci Technol. 2011;45(1):283-287.

26. Zhao CM, Wang WX. Importance of surface coatings and soluble silver in silver nanoparticles toxicity to Daphnia magna. Nanotoxicology. 2012;6(4):361-370. 
27. Alarcon EI, Udekwu K, Skog M, et al. The biocompatibility and antibacterial properties of collagen-stabilized, photochemically prepared silver nanoparticles. Biomaterials. 2012;33(19):4947-4956.

28. Kawai K, Narushima T, Kaneko K, et al. Synthesis and antibacterial properties of water-dispersible silver nanoparticles stabilized by metalcarbon $\sigma$-bonds. Appl Surf Sci. 2012;262:76-80.

29. Mout R, Moyano DF, Rana S, Rotello VM. Surface functionalization of nanoparticles for nanomedicine. Chem Soc Rev. 2012;41(7): 2539-2544.

30. Jaiswal S, Duffy B, Jaiswal AK, Stobie N, McHale P. Enhancement of the antibacterial properties of silver nanoparticles using beta-cyclodextrin as a capping agent. Int J Antimicrob Agents. 2010;36(3):280-283.

31. Frattine A, Pellegri N, Nicastro D, de Sanctis O. Preparation of amine coated silver nanoparticles using triethylenetetraamine. Mater Chem Phys. 2005;94:148-152.

32. Bin Ahmad M, Lim JJ, Shameli K, Ibrahim NA, Tay MY, Chieng BW. Antibacterial activity of silver bionanocomposites synthesized by chemical reduction route. Chem Cent J. 2012;6(1):101.

33. Singh S, Patel O, Jaiswal S, Prabhune AA, Ramana CV, Prasad BLV. A direct method for the preparation of glycolipid-metal nanoparticle conjugates sophorolipids as reducing and capping agents for the synthesis of water re-dispersible silver nanoparticles and their antibacterial activity. New J Chem. 2009;33:646-652.

34. Shameli K, Ahmad MB, Zamanian A, et al. Green biosynthesis of silver nanoparticles using Curcuma longa tuber powder. Int J Nanomedicine. 2017:5603-5610.

35. Irvani S. Green synthesis of metal nanoparticles using plants. Green Chem. 2011;13(10):2638-2650

36. Prakash P, Gnanaprakasam P, Emmanuel R, Arokiyaraj S, Saravanan M. Green synthesis of silver nanoparticles from leaf extract of Mimusops elengi, Linn. for enhanced antibacterial activity against multi drug resistant clinical isolates. Colloids Surf B Biointerfaces. 2013;108:255-259.
37. Khan M, Khan M, Adil SF, et al. Green synthesis of silver nanoparticles mediated by Pulicaria glutinosa extract. Int J Nanomedicine. 2013;8: 1507-1516.

38. Khan M, Mousa AA, Syamasundar KV, Alkhathlan HZ. Determination of chemical constituents of leaf and stem essential oils of Artemisia monosperma from central Saudi Arabia. Nat Prod Commun. 2012;7(8):1079-1082.

39. Khan M, Al-Mansour MA, Mousa AA, Alkhathlan HZ. Compositional characteristics of the essential oil of Myrtus communis grown in the central part of Saudi Arabia. J Essential Oil Res. 2014;26: 13-18.

40. Sathishkumar G, Gobinath C, Karpagam K, Hemamalini V, Premkumar K, Sivaramakrishnan S. Phyto-synthesis of silver nanoscale particles using Morinda citrifolia L. and its inhibitory activity against human pathogens. Colloids Surf B Biointerfaces. 2012;95: 235-240.

41. Masurkar SA, Chaudhari PR, Shidore VB, Kamble SP. Effect of biologically synthesised silver nanoparticles on Staphylococcus aureus biofilm quenching and prevention of biofilm formation. IET Nanobiotechnol. 2012;6(3):110-114.

42. Samberg ME, Orndorff PE, Monteiro-Riviere NA. Antibacterial efficacy of silver nanoparticles of different sizes, surface conditions and synthesis methods. Nanotoxicology. 2011;5(2):244-253.

43. Liu HL, Dai SA, Fu KY, Hsu SH. Antibacterial properties of silver nanoparticles in three different sizes and their nanocomposites with a new waterborne polyurethane. Int J Nanomedicine. 2010;5: 1017-1028.

44. Premanathan M, Karthikeyan K, Jeyasubramanian K, Manivannan G. Selective toxicity of $\mathrm{ZnO}$ nanoparticles toward Gram-positive bacteria and cancer cells by apoptosis through lipid peroxidation. Nanomedicine. 2011;7(2):184-192. 


\section{Supplementary materials}

A
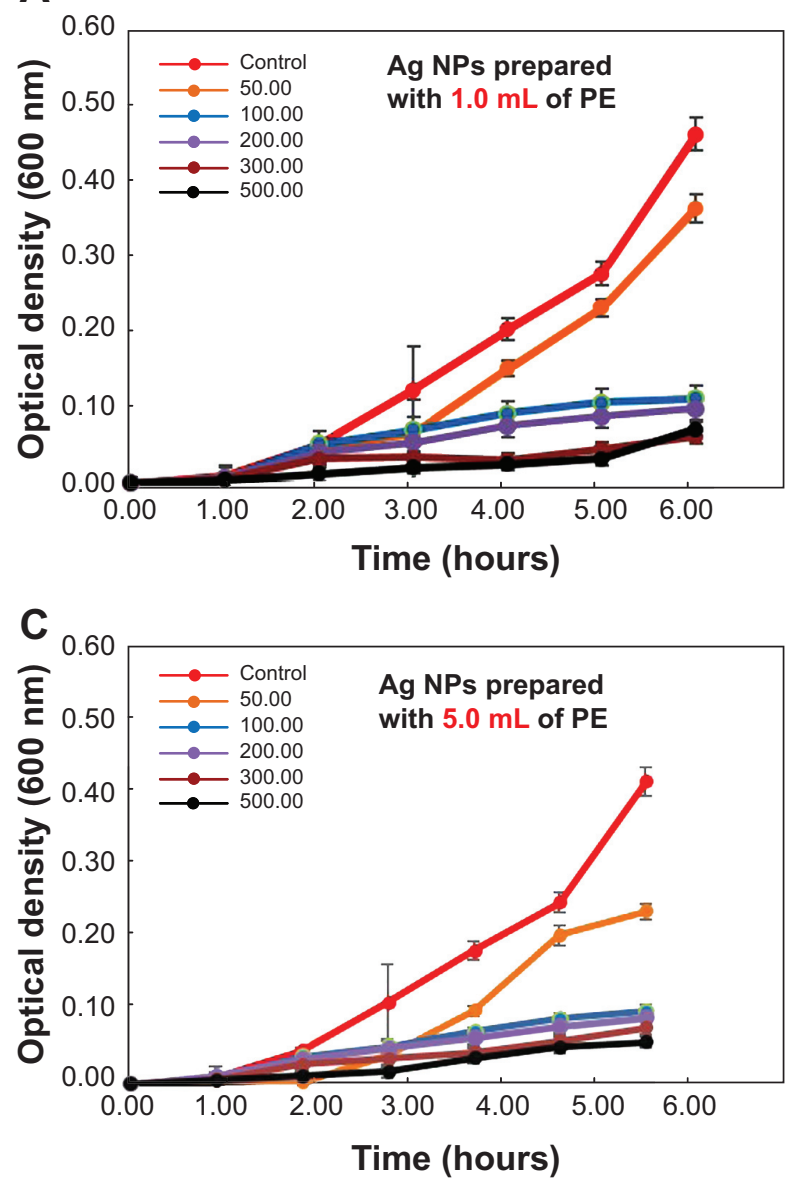

E

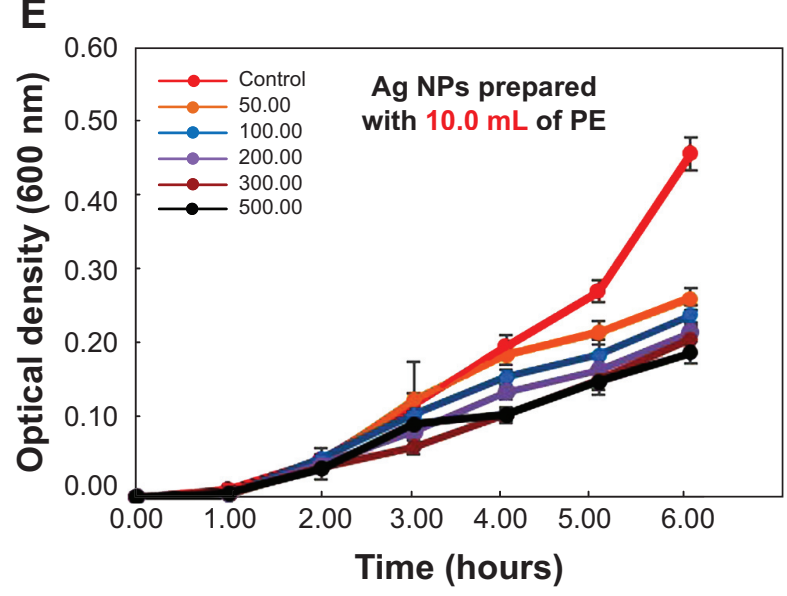

B
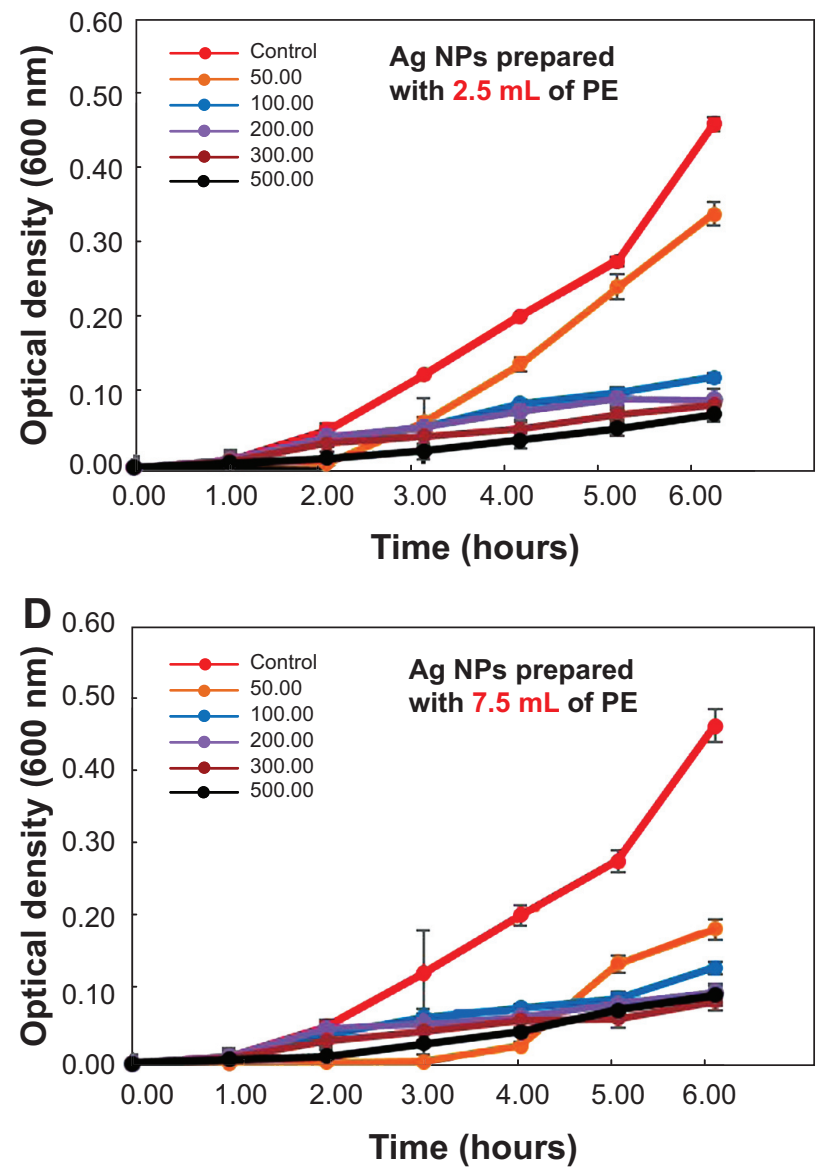

F

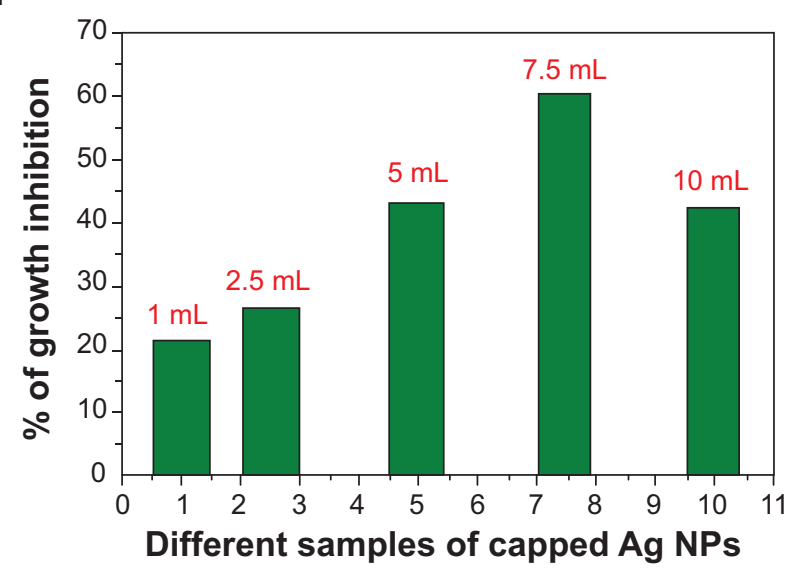

Figure SI Effect of various concentrations of capped Ag-nanoparticles (NPs)-plant extract (PE; 50-500 $\mu \mathrm{g} / \mathrm{mL}) \mathrm{prepared} \mathrm{with} \mathrm{(A)} 1.0 \mathrm{~mL}$, (B) $2.5 \mathrm{~mL}$, (C) $5.0 \mathrm{~mL}$, (D) $7.5 \mathrm{~mL}$, and (E) $10.0 \mathrm{~mL}$ Pulicaria glutinosa extract on the growth of Pseudomonas aeruginosa (the activity is presented in terms of change in optical density of a sample measured at a wavelength of $600 \mathrm{~nm}$ ). (F) Percentage growth inhibition of $P$. aeruginosa resulting from the capped Ag-NPs-PE (50 $\mu \mathrm{g} / \mathrm{mL}) \mathrm{prepared} \mathrm{with} \mathrm{different} \mathrm{concentrations} \mathrm{of} \mathrm{PE.}$ 
A
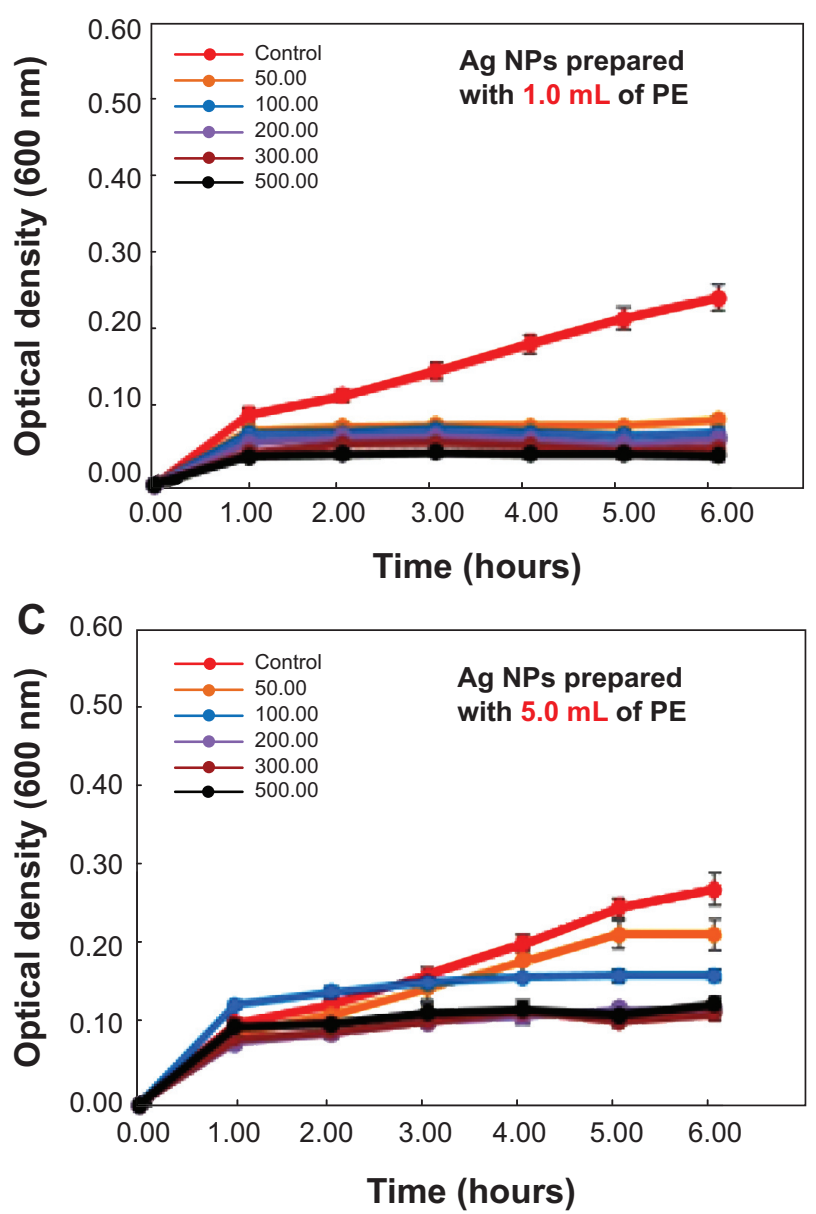

E

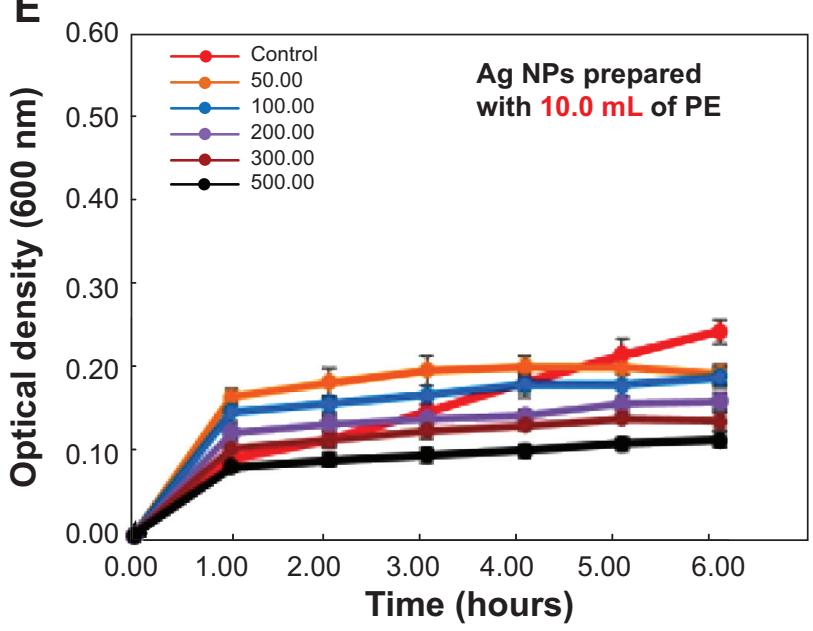

B
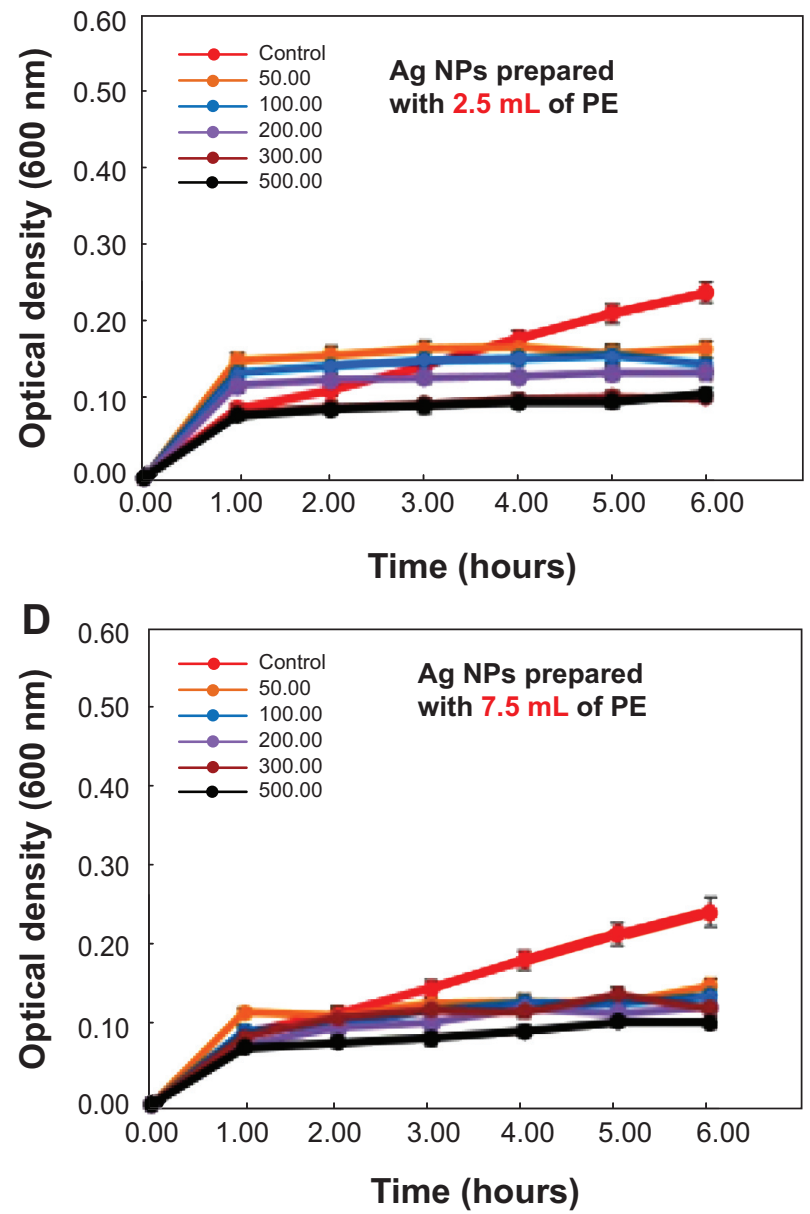

F



Ag NPs capped with various concentrations of PE

Figure S2 Effect of various concentrations of capped Ag-nanoparticles (NPs)-plant extract (PE; 50-500 $\mu \mathrm{g} / \mathrm{mL}) \mathrm{prepared} \mathrm{with} \mathrm{(A)} \mathrm{I.0} \mathrm{mL,} \mathrm{(B)} 2.5 \mathrm{~mL}$, (C) $5.0 \mathrm{~mL}$, (D) $7.5 \mathrm{~mL}$, and (E) $10.0 \mathrm{~mL}$ Pulicaria glutinosa extract on the growth of Micrococcus luteus (the activity is presented in terms of change in optical density of a sample measured at a wavelength of $600 \mathrm{~nm})$. (F) Percentage growth inhibition of M. luteus resulting from the capped Ag-NPs-PE (50 $\mu \mathrm{g} / \mathrm{mL}) \mathrm{prepared} \mathrm{with} \mathrm{different} \mathrm{concentrations} \mathrm{of} \mathrm{PE.}$ 
A



C

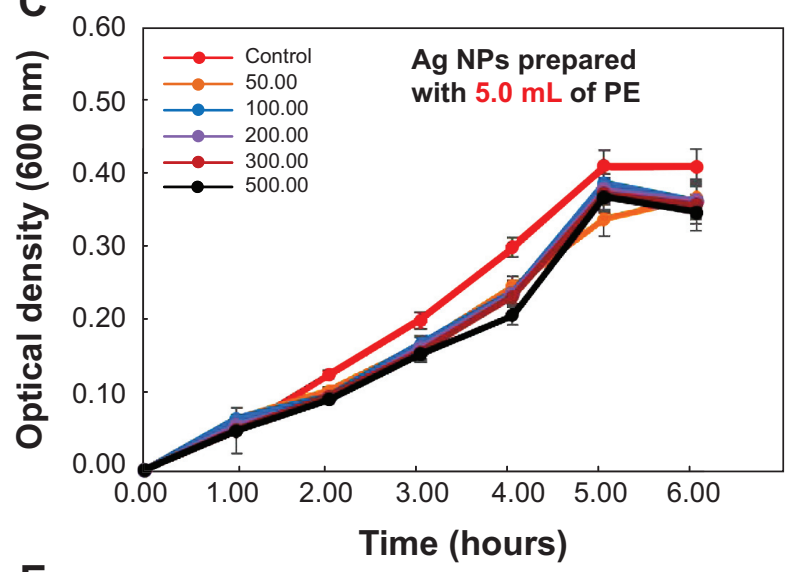

E

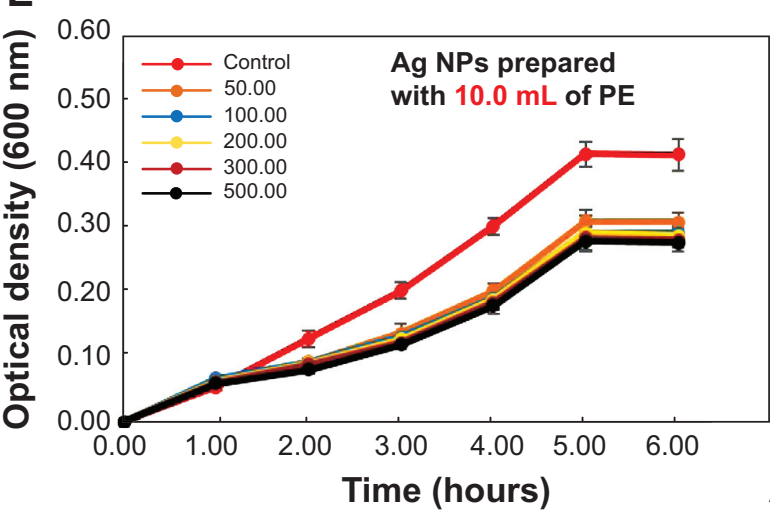

B



D

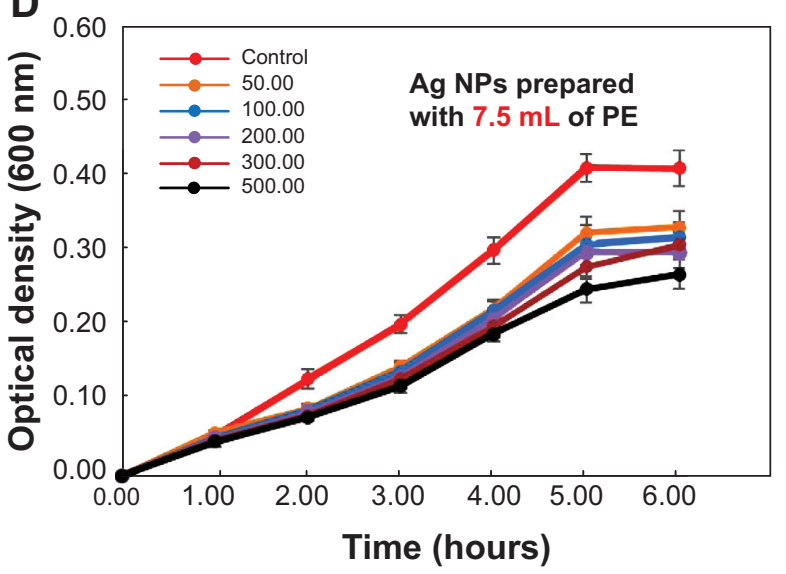

$\mathbf{F}$

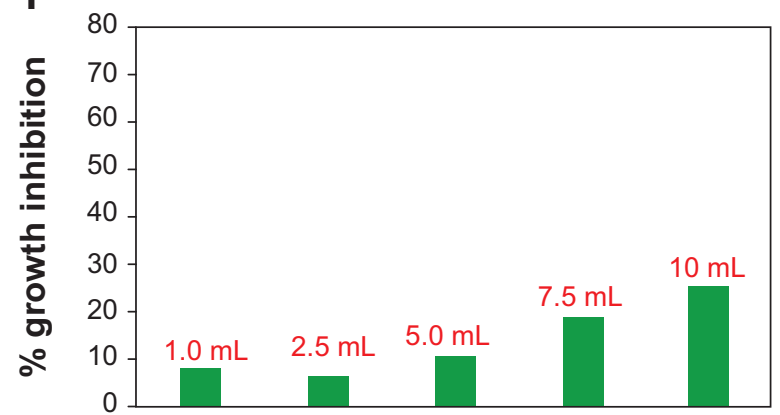

Ag NPs capped with various concentrations of PE

Figure S3 Effect of various concentrations of capped Ag-nanoparticles (NPs)-plant extract (PE; 50-500 $\mu \mathrm{g} / \mathrm{mL}) \mathrm{prepared} \mathrm{with} \mathrm{(A)} 1.0 \mathrm{~mL}$, (B) $2.5 \mathrm{~mL}$, (C) $5.0 \mathrm{~mL}$, (D) $7.5 \mathrm{~mL}$, and (E) $10.0 \mathrm{~mL}$ Pulicaria glutinosa extract on the growth of Staphylococcus aureus (the activity is presented in terms of change in optical density of a sample measured at a wavelength of $600 \mathrm{~nm})$. (F) Percentage inhibition of S. aureus growth resulting from the capped Ag-NPs-PE $(50 \mu g / \mathrm{mL}) \mathrm{prepared} \mathrm{with} \mathrm{different} \mathrm{concentrations} \mathrm{of} \mathrm{PE.}$

International Journal of Nanomedicine

\section{Publish your work in this journal}

The International Journal of Nanomedicine is an international, peerreviewed journal focusing on the application of nanotechnology in diagnostics, therapeutics, and drug delivery systems throughout the biomedical field. This journal is indexed on PubMed Central, MedLine, CAS, SciSearch $\AA$, Current Contents ${ }^{\circledR} /$ Clinical Medicine,

\section{Dovepress}

Journal Citation Reports/Science Edition, EMBase, Scopus and the Elsevier Bibliographic databases. The manuscript management system is completely online and includes a very quick and fair peer-review system, which is all easy to use. Visit http://www.dovepress.com/ testimonials.php to read real quotes from published authors. 